\title{
Medical conferences in the post-COVID world: a challenge, and an opportunity
}

\author{
European Society of Radiology (ESR)
}

Received: 28 April 2020 / Accepted: 30 April 2020 / Published online: 16 May 2020

(C) European Society of Radiology 2020

The current COVID-19 pandemic has struck humanity like a biblical or historical plague, with a rapidity rarely seen even during those previous events. From apparent beginnings in the Far East at the end of 2019, it has spread throughout the globe, causing over 3 million confirmed cases (with a much-higher probable prevalence) and over 200,000 deaths at the time of writing (April 27, 2020). Protective measures (personal and societal) to reduce the impact of the pandemic have impacted greatly on daily life in most parts of the world and have already produced enormous economic consequences for individuals, businesses and countries, with more to come. Uncertainty regarding the duration and geographical spread of the pandemic, the time needed to control it and the future availability of a cure or vaccine makes precise future planning impossible in virtually all aspects of life. We truly are living in "interesting times".

What is already evident is that the life changes we have experienced in recent months will be with us in some form for a long time, and that life after the pandemic will be different from before. We will have to adapt to a "new" normality in behaviours and relationships, informed by this experience. In some ways, current protective advice has roots in long-distant learning. During the 1665-1666 bubonic plague in England, the inhabitants of the Derbyshire village of Eyam were persuaded by their clergyman, Rev. William Mompesson, to quarantine themselves for 6 months to prevent the disease (which had spread from London to Eyam via fleas trapped in cloth) from spreading further. More than 260 of their

Please note that due to the time-sensitive nature of the work presented in this article, standard peer review has been bypassed to ensure rapid publication. The article has been directly assessed by the Editor-in-Chief.

European Society of Radiology (ESR)

communications@myesr.org

1 Vienna, Austria population of 700 died, whole families were wiped out, but the disease was contained, failing to reach nearby large populations in Sheffield and Manchester [1].

Healthcare professionals have been particularly affected by COVID-19, managing the difficult task of caring for those affected by the disease, and leading the way in advising governments on necessary actions. There is much we still do not know about the causative coronavirus, and the spectrum of disease it causes. As time goes on, we are learning that, while most cases present with flu-like symptoms (or suffer none at all), and a small proportion progress to severe respiratory distress, many other body systems and organs may be affected [2-4]. Robust data about pathologic changes induced by the infection are still incomplete, and the pathophysiology of the disease process is not yet fully understood.

And, of course, healthcare professionals have suffered a disproportionate death rate from COVID-19, resulting from their direct role in patient contact and care. Societies and patients owe a great debt of gratitude to those colleagues whose lives have been lost in the service of others.

Radiology has been affected by the pandemic in many ways. Our departments have rapidly implemented workflow changes to ensure timely service for acutely presenting patients, to protect other patients and staff from infection and to facilitate hospital-wide pathways designed to separate COVID-19 patients from non-infected ones [5-7]. Like all involved clinicians, radiologists have had to learn the features of the disease as they apply to our practice, including typical and atypical radiologic findings, appropriate use of imaging techniques (depending on available resources) and a correlation of findings with other clinical and laboratory data $[6,8,9]$.

The effects on scientific societies have been dramatic. Planned activities have had to be changed at short notice, new COVID-19 activity has had to be arranged quickly and most have been obliged to alter, postpone or cancel planned meetings. Nor is this confined to academia. The first large 
gathering cancelled in Europe was the Geneva Motor Show, scheduled for March 5 to 15,2020. One of the earliest medical conferences affected was the European Congress of Radiology, which was planned for March 11 to 15, 2020 (and which will now take place in an online-only format from July 15 to 19, 2020). Many other conferences have been similarly affected; no one yet knows when face-to-face conferences can safely resume, and what restrictions may still be necessary when they do.

The main goal of any medical society is to promote and facilitate collaborative work and growth; this goal cannot be met if members cannot meet (face-to-face or virtually). A recent editorial by Evens outlines the many aims of professional meetings: education and research, policy-making, career and professional skills development, marketing by participating companies and interaction among colleagues at the meeting itself and at associated social functions [10]. How can we achieve all, or most of these aims if it is not possible to meet in person?

It is feasible to switch from an on-site to an online meeting format and still meet most of the goals of a "conventional" medical conference, although it is challenging. Some societies are already attempting this: the American College of Cardiology held its virtual meeting from March 28 to 30, 2020, and the European Society of Radiology and European Association of Urology will hold online conferences in July 2020. Many of the necessary techniques are well established. Recording and streaming of conference sessions for later on-demand viewing has been offered by some societies (including the ESR) for some years. Live webinars are common educational tools (and have been offered by the ESR on COVID-related topics since March 2020). However, a full congress is a more-complex proposition, involving a variety of session types, aimed at diverse types of attendees, with many different forms of interaction between speakers and delegates. Future online (or hybrid) conferences must find or invent new methods of allowing discussions and interactions involving remote participants during all sessions, to create the same sense of community and collective learning that can be felt during successful on-site events. This will not be easy, but making this necessary shift successfully will establish a new standard for what defines medical conference success in the future.

The COVID-19 pandemic has changed how humans interact with each other, and these changes are likely to persist, at least for some years. If scientific societies wish to remain relevant to their members and successful, they must adapt to this new reality. Scientific meetings must change their structure to survive, and successful societies in the future will be those which embraced this new circumstance, and adapted early. Future conferences will be different from those of yore, and we must learn not to judge them by old standards. The mould is broken; the new, online ECR 2020 will be a different meeting, with a different structure and different outcomes. It will be the first, and the best (so far) of a new generation.

Acknowledgements This Editorial was prepared by the members of the ESR Board of Directors: Boris Brkljačić (Chairman of the ESR Board of Directors), Michael Fuchsjäger (ESR President), Regina Beets-Tan (ESR 1st Vice President), Adrian P. Brady (ESR 2nd Vice President) and Lorenzo E. Derchi (Past President).

Funding information The authors state that this work has not received any funding.

\section{Compliance with ethical standards}

Guarantor The scientific guarantor of this publication is Boris Brkljačić.

Conflict of interest The authors of this manuscript declare no relationships with any companies, whose products or services may be related to the subject matter of the article.

Statistics and biometry No complex statistical methods were necessary for this paper.

Informed consent Written informed consent was not required for this study because this work is an Editorial.

Ethical approval Institutional review board approval was not required because this work is an Editorial.

Methodology

- retrospective

- observational

\section{References}

1. Rich T (2020) Eyam: the village that sacrificed itself to the plague and the lessons it can teach us. The Independent. https://inews.co. uk/news/eyam-village-sacrifice-plague-17th-century-coronavirusuk-lockdown-2522801. Accessed 27 Apr 2020

2. Wong SH, Lui RN, Sung JJ (2020) Covid-19 and the digestive system. J Gastroenterol Hepatol. https://doi.org/10.1111/jgh.15047

3. Mao L, Jin H, Wang M, Hu Y, Chen S, He Q, Chang J, Hong C, Zhou Y, Wang D, Miao X, Li Y, Hu B (2020) Neurologic manifestations of hospitalized patients with coronavirus disease 2019 in Wuhan, China. JAMA Neurol. https://doi.org/10.1001/ jamaneurol.2020.1127

4. Long B, Brady WJ, Koyfman A, Gottlieb M (2020) Cardiovascular complications in COVID-19. Am J Emerg Med. https://doi.org/10. 1016/j.ajem.2020.04.048

5. Chen RC, Tan TT, Chan LP (2020) Adapting to a new normal? 5 key operational principles for a radiology service facing the COVID-19 pandemic. Eur Radiol. https://doi.org/10.1007/ s00330-020-06862-1

6. Revel M, Parkar AP, Prosch H et al (2020) COVID-19 patients and the radiology department - advice from the European Society of Radiology (ESR) and the European Society of Thoracic Imaging (ESTI). Eur Radiol. https://doi.org/10.1007/s00330-020-06865-y

7. Politi LS, Balzarini L (2020) The radiology department during the COVID-19 pandemic: a challenging, radical change. Eur Radiol. https://doi.org/10.1007/s00330-020-06871-0 
8. Zhang R, Ouyang H, Fu L et al (2020) CT features of SARS-CoV-2 pneumonia according to clinical presentation: a retrospective analysis of 120 consecutive patients from Wuhan City. Eur Radiol. https://doi.org/10.1007/s00330-020-06854-1

9. Kim H, Hong H, Yoon SH (2020) Diagnostic performance of CT and reverse transcriptase-polymerase chain reaction for coronavirus disease 2019: a meta-analysis. Radiology. https://doi.org/10.1148/ radiol.2020201343
10. Evens RG (2020) The impact of a pandemic on professional meetings. Radiology: Imaging Cancer. https://doi.org/10.1148/rycan. 2020204012

Publisher's note Springer Nature remains neutral with regard to jurisdictional claims in published maps and institutional affiliations. 